\title{
Use of a whole blood assay to monitor the immune response to mycobacterial antigens in leprosy patients: a predictor for type 1 reaction onset?
}

\author{
R. E. WEIR, C. R . BUTLIN*, K. D. NEUPANE*, \\ S. S. FAILBUS ${ }^{*}$, H. M. DOCKRELL \\ Immunology Unit, Department of Infectious and Tropical Diseases, \\ London School of Hygiene \& Tropical Medicine, Keppel Street, \\ London WC1E 7HT UK; ${ }^{*}$ The Leprosy Mission, Anandaban Leprosy \\ Hospital, PO Box 151, Kathmandu, Nepal
}

\section{Accepted for publication 3 July 1998}

Summary Longitudinal studies are more appropriate than cross-sectional studies for investigating changes in the immune response to Mycobacterium leprae during leprosy, such as occur in type 1 (reversal) reactions. A test for predicting the onset of reactions in leprosy would greatly reduce disability associated with leprosy. Whole blood assays are appropriate for longitudinal studies of the in vitro T-cell response, as they are robust and reproducible, and require only a small volume of blood. Whole blood assays were used to assess the natural variation in the 'normal' T-cell response to mycobacterial antigens in healthy UK donors, and healthy Nepali donors, tested over 6 months. This was compared with variation in T-cell responses measured over 6 months in 22 leprosy patients in Nepal, including eight who developed type 1 reactions during this time. The in vitro $\mathrm{T}$-cell response to $M$. leprae sonicate, M. tuberculosis PPD, the mitogen PHA, and (in the UK study) recombinant mycobacterial antigens ( $70 \mathrm{kD}$ and $30 / 31 \mathrm{kD}$ proteins) was measured by lymphoproliferation and interferon-gamma (IFN $\gamma$ ) responses, and variation in responses over time in each subject calculated as a coefficient of variation (CV). The baseline high, low or non-responder status of the healthy UK donors remained stable. The magnitude of IFN $\gamma$ responses varied by mean $\mathrm{CV}$ ranging from $26 \%$ (to PPD) to $63 \%$ (to Mtb $70 \mathrm{kD}$ ); proliferation responses showed less variation, ranging from mean $\mathrm{CV}$ of $18 \%$ (to PHA) to $47 \%$ (to Mtb $70 \mathrm{kD}$ ). Response variation was independent of lymphocyte number in culture. Similiar variation in lymphoproliferation responses to MLS, PPD and PHA was observed in the group of healthy Nepali subjects, and in Nepali leprosy patients who did not experience reactions during the study. Of the eight leprosy patients who developed type 1 reactions, four (two BT, one $\mathrm{BB}$, one $\mathrm{BL}$ ) showed significantly increased proliferation to MLS at the time of reaction (74-300\% above baseline); four (one BB, two BL, one LL) remained low or non-responders to MLS throughout. An alternative marker of immune responseanti-phenolic glycolipid-1 (PGL-1) antibody titre-was not predictive of reaction onset in these patients. This study demonstrated that whole blood assays provide 
reproducible in vitro measurements that can be used to monitor changes in T-cell responses to $M$. leprae antigens; their practical use as a diagnostic marker of type 1 reaction onset is discussed.

\section{Introduction}

Studies of the human in vitro T-cell mediated immune response to $M$. leprae and constituent antigens are usually cross-sectional, with subjects tested at a single time point. It is becoming increasingly clear that the cell-mediated immune response is dynamic, exhibiting diurnal rhythmicity, ${ }^{1}$ and influenced by hormonal changes ${ }^{2,3}$ and concurrent infections. ${ }^{4}$ Thus, it is important to be able to estimate the natural variability of in vitro $\mathrm{T}$-cell responses, in order to evaluate the significance of responses measured in cross-sectional studies. A limitation to longitudinal analysis of T-cell mediated responses in sufficiently large study groups has been the large volume of blood required from the subject for each test. This problem has now been overcome with the development of whole blood assays, which can analyse lymphocyte proliferative and cytokine responses to antigens in a very small volume of blood. Whole blood assays have been used in longitudinal analyses of cellular responses in different infectious diseases, such as $\mathrm{HIV}^{5}$, leishmaniasis ${ }^{6}$ and meningitis. ${ }^{7}$ A whole blood assay has also been developed to analyse in vitro T-cell responses to $M$. leprae antigens. ${ }^{8}$

The symptoms of leprosy, including skin lesions and neuritis, are manifestations of the host immune response to infection with $M$. leprae $^{9}$ Shifts in the immune response are most clearly indicated by the clinical symptoms of type 1 'reversal' reactions, frequently associated with borderline (BT/BB) leprosy, and type 2 erythema nodosum leprosum (ENL) reactions, associated with borderline lepromatous and lepromatous (BL/LL) leprosy. Reactions are the principal cause of disability in leprosy patients, as nerves local to the reaction can become irreversibly damaged. ${ }^{10,11}$ The exact factors that precipitate onset of reactions have not yet been defined, although a sudden increase in $M$. leprae antigens released as a result of drug-induced bacterial killing may be a major factor. The first 6-12 months of multi-drug therapy (MDT) is considered to be the period of highest risk for the development of type 1 reactions. Both type 1 and type 2 reactions can be controlled with the steroid prednisone, indicating that an increase of pro-inflammatory activity against $M$. leprae, including release of the cytokine interferon-gamma (IFN $\gamma$ ), may be involved in the onset of reactions. ${ }^{12,13}$ However, steroid treatment often starts long after the initiation of the inflammatory process, by which time nerve damage has occurred.

A means of predicting the onset of reactions would greatly reduce the incidence of disability in leprosy. Longitudinal studies of leprosy patients undergoing reactions have found increased levels of circulating soluble IL2 receptor ${ }^{14-16}$ and $\beta 2$-microglobulin ${ }^{17}$ in both types of reaction, and increased serum $\mathrm{IgG} 1^{18}$ and $\mathrm{TNF} \alpha^{19}$ in type 2 reactions, as evidence of the increased immune response underlying reactions. Lepromin positivity (indicating T-cell responsiveness to $M$. leprae), and a positive skin smear, and seropositivity for anti-PGL-1 antibodies (indicating a high antigen load which may predominate in the nerves), have been found to be associated with the tendency of leprosy patients to develop type 1 reactions. ${ }^{20,}{ }^{21}$ As an alteration in the T-cell response to $M$. leprae is likely to be the primary event in a reaction, monitoring of the in vitro $\mathrm{T}$-cell response could provide an appropriate indicator of reaction onset. Previous studies have carried out lymphocyte transformation tests to measure the response to $M$. leprae in patients before, during and 
after type 1 reaction, and have reported increased responses during reactions. ${ }^{22,23}$ However, these studies did not attempt to define the normal variability of the human T-cell response to $M$. leprae, and some post-reaction responses were measured while the patient was still receiving immunosuppressive steroid treatment.

Therefore a more thorough assessment of the natural variability of the $M$. leprae-specific $\mathrm{T}$-cell response, and the implications of changes in this for development of type 1 reaction onset, is required. Using the whole blood assay, a longitudinal study of healthy subjects in the UK was performed, to analyse the variability of T-cell responses measured every month for 6 months to M. leprae antigen [M. leprae sonicate (MLS)] in these subjects. Responses were also measured to $M$. tuberculosis purified protein derivative (PPD), and defined recombinant proteins derived from M. le prae (30-32 kD) and M. tuberculosis $(70 \mathrm{kD})$ - these antigens are shared with other mycobacterial species and are therefore likely to be recognised by UK donors. Response variation in the UK subjects was compared with that measured (using identical protocols) in a group of healthy control subjects in a leprosy-endemic region of Nepal, to investigate whether increased exposure to M. leprae and M. tuberculosis in Nepal might affect the variability of responses. These baseline data were used to assess variation of T-cell responses to MLS and PPD in a group of leprosy patients in Nepal, some of whom experienced type 1 reactions during the course of the study. Variation in sequential anti-PGL-1 antibody responses in the patients was also assessed, as an additional marker of immune response change.

\section{Materials and methods}

SUBJECTS

In the UK, six laboratory personnel [all Caucasian; three male, three female; mean age 29 (range 25-40)] were recruited. All were BCG vaccinated; none came into contact with a leprosy case during the course of the study. In Nepal, a control group of 11 staff donors [nine Nepali/Indian, two Caucasian; eight male, three female; mean age 30 years (range 25-40)] who were leprosy free at the time of testing was recruited. All were currently working in the leprosy hospital so would be expected to have greater contact with $M$. leprae than the average Nepali resident. Seventy-four leprosy patients, who were either untreated and just starting, or had recently started, MDT treatment, were recruited through the outpatient clinic of Anandaban Leprosy Hospital, Kathmandu, Nepal, over a 2-month period. A small blood sample was obtained from each study subject following their informed consent. All subjects were subsequently tested once a month (when possible) over a 6-month period, in both UK and Nepal. Patients were retested on subsequent visits to the hospital, when detailed clinical records were taken and signs of onset of type 1 or 2 reactions were noted. Plasma isolated from the patient blood samples was tested for anti-PGL-1 IgM antibodies using the standard technique for detection in serum ${ }^{20}$ (paired serum and plasma samples were tested and found to be comparable). Ethical permission for the study was obtained from the Ethics Committees at the LSH\&TM, and Anandaban Hospital.

\section{WHOLE BLOOD ASSAYS}

Whole blood assays, lymphocyte proliferation measurements and IFN $\gamma$ ELISAs were carried out as previously described. ${ }^{8}$ Whole blood was diluted 1 in 10 with RPMI tissue culture 
medium (Gibco BRL, Paisley, Scotland) supplemented with $100 \mathrm{IU}$ penicillin/100 $\mu \mathrm{g}$ streptomycin/2 mM L-glutamine/ml (all Gibco), and incubated with antigen, and positive and negative control stimuli, in triplicate tissue culture wells. The cultures were pulsed with tritiated thymidine $\left({ }^{3} \mathrm{H}\right) \mathrm{TdR}$ after 6 days incubation, harvested and counted in a scintillation counter. In the UK study, triplicate culture supernatants were harvested on day 6 , pooled and frozen at $-20^{\circ} \mathrm{C}$ for batch testing for IFN $\gamma$ by ELISA at the end of the study. Total and differential leukocyte counts were performed on each blood sample and the number of lymphocytes per culture for each subject was calculated.

\section{ANTIGENS}

Cultures were incubated with M. leprae sonicate (MLS, batch CD215; Dr R. Rees, NIMR, Mill Hill, UK) and and M. tuberculosis PPD (Statens Seruminstitut, Copenhagen, Denmark). The mitogen phytohaemagglutinin (PHA; Sigma, Poole, UK) and tissue culture medium were used as positive and negative controls, respectively. In the UK study, recombinant $M$. leprae 30/ $31 \mathrm{kD}$ protein (Ag 85B; kindly provided by Dr B. Wieles, Leiden, The Netherlands) and M. tuberculosis $70 \mathrm{kD}$ protein (Mtb $70 \mathrm{kD}$; MT-70-6A, Dr J. van Embden, Bilthoven, The Netherlands) were also tested. The same batches of antigens were used throughout each study. The antigens were initially tested at 1,10 and $30 \mu \mathrm{g} / \mathrm{ml}$, and PHA at $5 \mu \mathrm{g} / \mathrm{ml}$.

\section{DATA ANALYSIS}

Proliferation results are presented as the mean $\left({ }^{3} \mathrm{H}\right) \mathrm{TdR}$ incorporation of triplicate cultures, after subtraction of background counts in the negative control wells (dDPM). The threshold for a positive response (calculated as $2 \times$ mean SD above the mean negative control culture responses in 37 subjects; data not shown) was $500 \mathrm{dpm}$. IFN $\gamma$ responses are presented as mean IFN $\gamma$ measurements (IU/ml) of duplicate ELISA wells, after subtraction of any background measurement in the negative control culture supernatant (undetectable in the majority of cultures); a measurement greater than zero was regarded as a positive IFN $\gamma$ response. The variation in $\mathrm{dpm}$ measurements in triplicate cultures was calculated for one subject (UK/donor 1 , in response to PPD) and found to be $5 \%$ on average. Anti-PGL-1 antibody measurements are presented as mean optical density (OD) at $492 \mathrm{~nm}$. Interplate variation was controlled by the inclusion of positive and negative control samples on every plate, and was found to be less than $10 \% .^{20}$

Variation in responses over time, to each antigen in each subject tested at least three times, was calculated as a coefficient of variation (CV), where

$$
\mathrm{CV}=\frac{\mathrm{SD} \text { (sequential response measurements) }}{\text { mean (sequential response measurements) }} \times 100 \%
$$

Other statistical tests are detailed where used.

\section{Results}

VARIATION OVER TIME OF DOSE RESPONSE TO ANTIGEN IN UK SUBJECTS

The optimal dose was found to be $10 \mu \mathrm{g} / \mathrm{ml}$ for all antigens (results not shown), although most subjects made a response to antigen at $1 \mu \mathrm{g} / \mathrm{ml}$. Subjects in the UK study were routinely tested 
with antigen at 1 and $10 \mu \mathrm{g} / \mathrm{ml}$ to assess whether the dose-response profile changed over time. Figure 1 shows results for IFN $\gamma$ responses to PPD and MLS in one subject, tested once a month for 6 months. The dose response to PPD did appear to vary, with the response to $1 \mu \mathrm{g} /$ $\mathrm{ml}$ relatively higher on some months; however, for responses to both PPD and MLS, the optimum dose was always $10 \mu \mathrm{g} / \mathrm{ml}$.

VARIATION IN RESPONSES TO ANTIGEN AND MITOGEN IN CONTROL SUBJECTS

The six healthy UK control subjects were tested over the course of 6 months. Proliferation responses (Figure 2) and IFN $\gamma$ responses (Figure 3) to PPD, MLS, M.tb $70 \mathrm{kD}$ protein and

\section{Dose response to PPD}
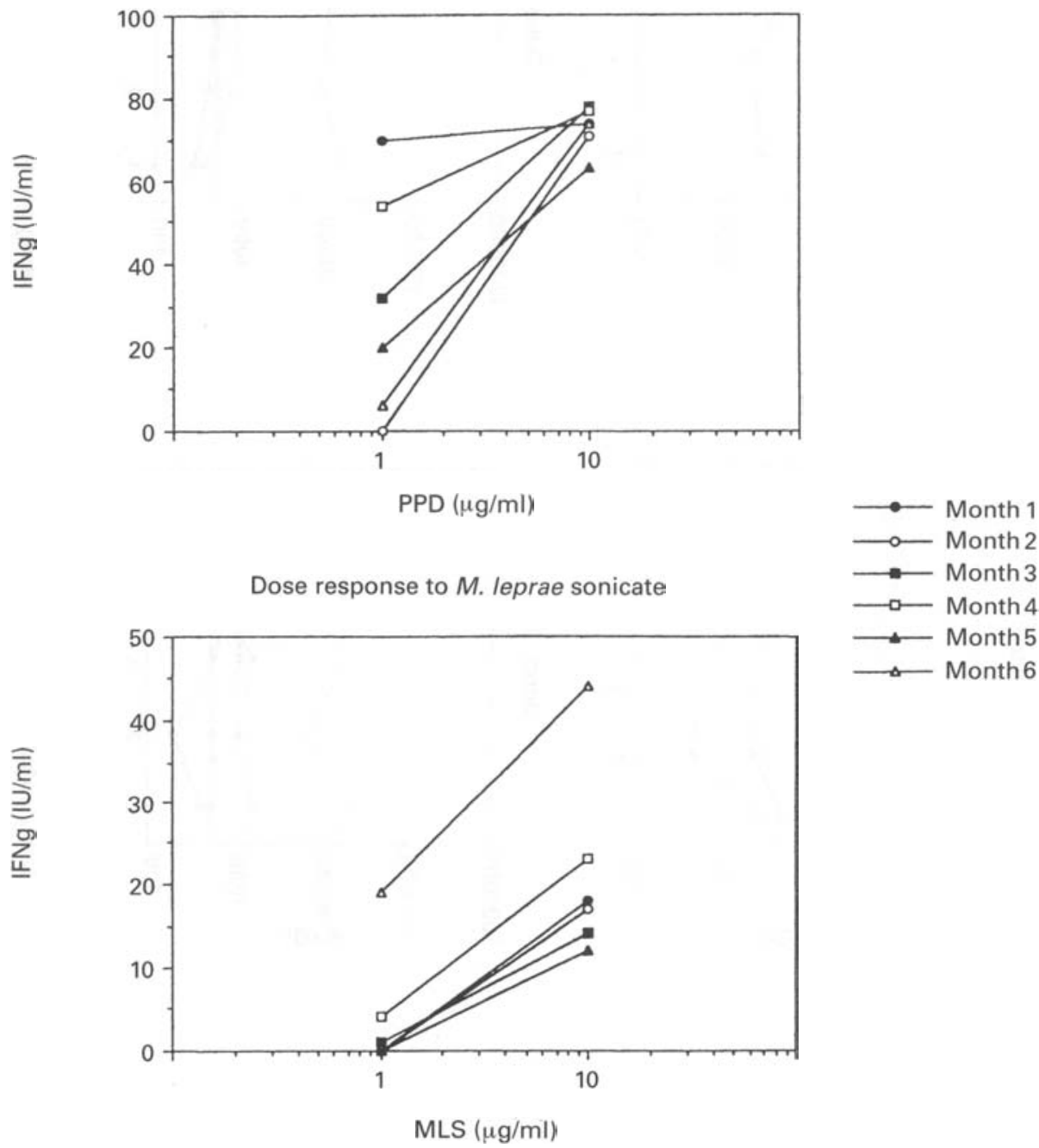

Figure 1. Dose response to PPD and M. leprae sonicate (MLS) at 1 and $10 \mu \mathrm{g} / \mathrm{ml}$, in whole blood cultures from one UK donor tested at monthly intervals, measured by IFN $\gamma$ production $(\mathrm{U} / \mathrm{ml})$ in day 6 culture supernatants. 
Donor 1

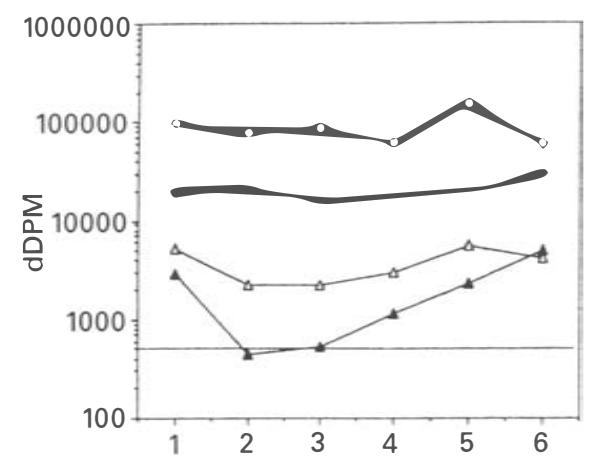

Donor 3

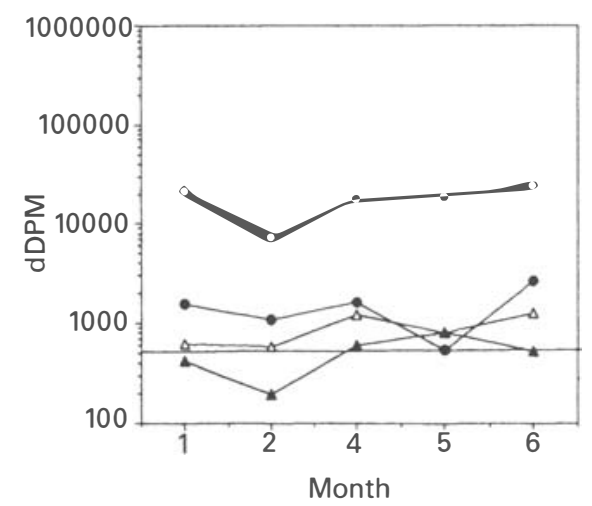

Donor 2

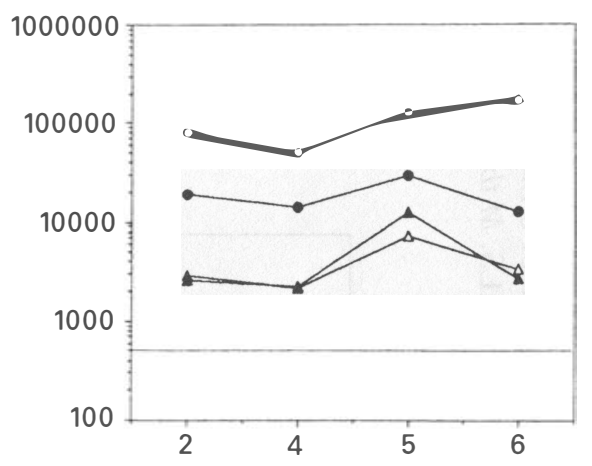

Donor 4

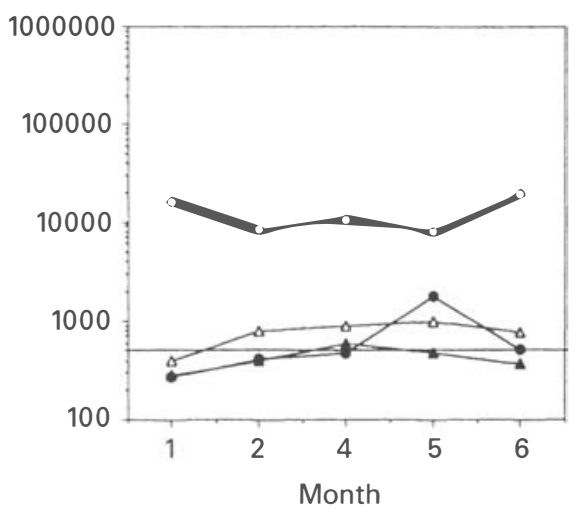

Figure 2. Proliferation responses (dDPM) in whole blood cultures from four UK donors, tested repeatedly over the course of 6 months. Cultures were stimulated with $M$. leprae sonicate $(\bullet)$, M. leprae $30 / 31 \mathrm{kD}$ protein $(\mathbf{\Lambda})$, PPD $(O)$ and $M$. tuberculosis $70 \mathrm{kD}$ protein $(\Delta)$ at $10 \mu \mathrm{g} / \mathrm{ml}$, and proliferation measured after 7 days culture. The positive response threshold $(500 \mathrm{dpm})$ is indicated by a line. 
Donor 1

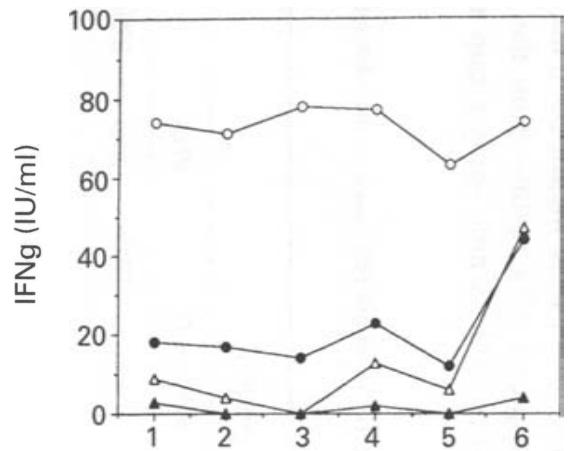

Donor 3

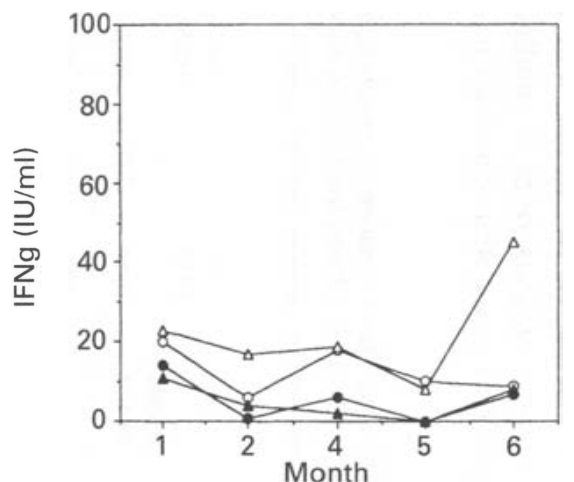

Donor 2

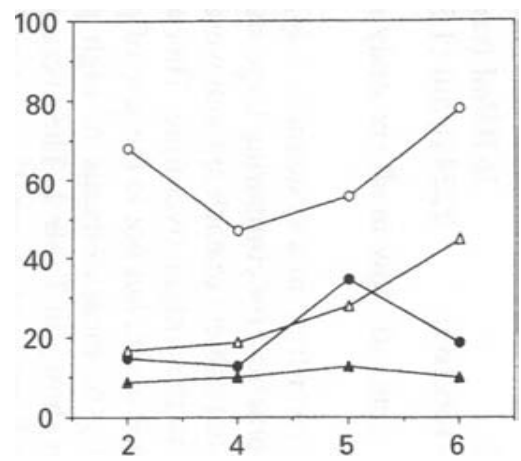

Donor 4

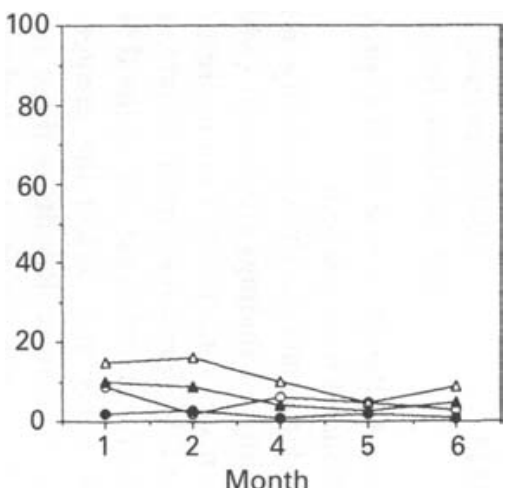


M. leprae 30-31 kD protein are shown for four subjects tested four or more times during the study. For both IFN $\gamma$ and proliferation measurements, donors 1 and 2 made consistently high or moderate responses to PPD, MLS and $M t b 70 \mathrm{kD}$, while donors 3 and 4 were consistently moderate responders to PPD and low or non-responders to MLS and $M t b 70 \mathrm{kD}$. The group average proliferation $(\mathrm{dpm})$ and $\mathrm{IFN} \gamma(\mathrm{IU} / \mathrm{ml})$ responses to each antigen were:

$\begin{array}{lcc}\text { PPD } & 67,421 \mathrm{dpm} \text { (range 12,409-112,411); } & 46 \mathrm{IU} / \mathrm{ml} \text { (range 5-91) } \\ \text { MLS } & 11,079 \mathrm{dpm} \text { (range 0-20,269); } & 20 \mathrm{IU} / \mathrm{ml} \text { (range 2-60) } \\ \text { Mtb 70 kD } & 2,048 \mathrm{dpm} \text { (range 0-3,945); } & 26 \mathrm{IU} / \mathrm{ml}(\text { range 11-52) } \\ \text { PHA } & 124,765 \mathrm{dpm} \text { (range 87,603-166,169); } & 2224 \mathrm{IU} / \mathrm{ml}(1,320-2,901) \text {. }\end{array}$

Responses to the M. leprae $30 / 31$ D protein were generally low in all six study subjects and were excluded from analysis.

In order to analyse the variability in response over time in a systematic way, rather than representing the findings graphically (which is impractical for comparing large study groups), coefficients of variation (CV) of the response in each subject to each antigen were calculated. A higher $\mathrm{CV}$ represents a more variable response to the antigen over time. This was found to be inversely related to the size of the IFN $\gamma$ response made, but not to the size of proliferation response-this may reflect the greater variability of measurements of high proliferation responses in culture. Results of these analyses are shown in Table 1. The average CV for all six donors to each antigen was calculated, as an indication of 'normal' variation in responses to each of these mycobacterial antigens in UK donors.

Proliferation responses were less variable than IFN $\gamma$ responses (paired $t$-test, $p=0 \cdot 015$ ), and may therefore be a more reproducible measure of the T-cell response to $M$. leprae antigens in longitudinal studies. We have previously found that proliferation and IFN $\gamma$ responses parallel each other in these donors (data not shown).

Proliferation responses to PPD and MLS, and to PHA, were measured in the group of 11 Nepali control subjects over 6 months, and compared with results from the UK cohort. Average $\mathrm{CV}$ of sequential responses to each antigen in the whole study group are shown in

Table 1. Coefficients of variation for proliferation and interferon-gamma responses to mycobacterial antigens in sequential whole blood cultures from six UK donors

\begin{tabular}{|c|c|c|c|c|c|c|c|c|c|c|}
\hline \multirow[b]{3}{*}{ Donor } & \multirow{3}{*}{$\begin{array}{l}\text { Number } \\
\text { of tests }\end{array}$} & \multicolumn{8}{|c|}{$\mathrm{CV}(\%)$} & \multirow[b]{3}{*}{ Cell no. } \\
\hline & & \multicolumn{2}{|l|}{ PPD } & \multicolumn{2}{|l|}{ MLS } & \multicolumn{2}{|c|}{ Mtb $70 \mathrm{kD}$} & \multicolumn{2}{|l|}{ PHA } & \\
\hline & & dpm & $\mathrm{IFN} \gamma$ & dpm & $\mathrm{IFN} \gamma$ & dpm & $\mathrm{IFN} \gamma$ & dpm & $\mathrm{IFN} \gamma$ & \\
\hline 1 & 6 & 37 & 7 & 23 & 55 & 61 & 130 & 24 & 42 & 27 \\
\hline 2 & 4 & 47 & 22 & 41 & 49 & 58 & 47 & 13 & 27 & 33 \\
\hline 3 & 5 & 35 & 48 & 52 & 100 & 36 & 61 & 17 & 17 & 30 \\
\hline 4 & 5 & 39 & 55 & - & 46 & - & 41 & 30 & 36 & 5 \\
\hline 5 & 3 & 13 & 14 & 11 & 31 & 21 & 45 & 16 & 53 & 53 \\
\hline 6 & 3 & 26 & 11 & 86 & 88 & 61 & 52 & 7 & 69 & 23 \\
\hline \multicolumn{2}{|c|}{ Group average } & 33 & 26 & 42 & 61 & 47 & 63 & 18 & 41 & 28 \\
\hline
\end{tabular}

$\mathrm{dpm}=\%$ coefficient of variation of proliferation measurements over sequential tests.

IFN $\gamma=\%$ coefficient of variation of IFN $\gamma$ measurements over sequential tests.

cell no. $=\%$ coefficient of variation of mean lymphocyte number per culture.

$-=$ no detectable response so CV could not be calculated. 
Table 2. Variation of sequential measurements of proliferation responses to mycobacterial antigens in Nepali healthy controls and leprosy patients

\begin{tabular}{|c|c|c|c|c|c|c|c|}
\hline Group & $n$ & $\begin{array}{c}\text { PPD } \\
x\end{array}$ & $\begin{array}{l}\text { Mean } \\
\% \mathrm{CV}\end{array}$ & $\begin{array}{c}\text { MLS } \\
\mathrm{x}\end{array}$ & $\begin{array}{l}\text { Mean } \\
\% \mathrm{CV}\end{array}$ & $\begin{array}{c}\text { PHA } \\
x\end{array}$ & $\begin{array}{l}\text { Mean } \\
\% \text { CV }\end{array}$ \\
\hline Endemic controls & 11 & 73,600 & 37 & 15,166 & 69 & 78,017 & 29 \\
\hline $\begin{array}{l}\text { Leprosy patients: } \\
\text { TT/BT (no reaction) } \\
\text { BB/BL/LL (no reaction) }\end{array}$ & $\begin{array}{l}7 \\
5\end{array}$ & $\begin{array}{l}58,629 \\
30,128\end{array}$ & $\begin{array}{l}49 \\
62\end{array}$ & $\begin{array}{r}20,674 \\
0\end{array}$ & $\begin{array}{r}57 \\
-\end{array}$ & $\begin{array}{l}67,755 \\
69,561\end{array}$ & $\begin{array}{l}40 \\
15\end{array}$ \\
\hline Total patient mean & & & 55 & & - & - & 27 \\
\hline
\end{tabular}

$\mathrm{x}=$ mean proliferation measurement $(\mathrm{dpm})$ of sequential test cultures.

$\% \mathrm{CV}=\%$ coefficient of variation of proliferation measurements over sequential tests.

Table 2. The average variation observed in this group of hospital staff control donors was similiar to that seen in the UK donors to PPD, but higher to MLS (and PHA).

\section{VARIATION OF LYMPHOCYTE NUMBERS IN CULTURE}

The lymphocyte number in whole blood cultures is not routinely estimated. To investigate whether this may influence magnitude of responses, lymphocyte numbers in culture were counted at each test point, and are summarized in Table 1 for the UK control subjects. The average lymphocyte number per culture was $3.64 \times 10^{4}$; the average $\mathrm{CV}$ of lymphocyte number for the six subjects over the testing period was $28 \%$. Lymphocyte number was compared with proliferation and IFN $\gamma$ responses to the antigens. There was no positive correlation between lymphocyte number and responses to any of the antigens, in either the UK or the Nepali control groups. Responses to PHA also did not correlate with lymphocyte number; this may be due to responses being measured on day 6 , after the optimal day of response to PHA (day 3).

\section{RESPONSE VARIATION IN NEPALI LEPROSY PATIENTS}

Of the initial cohort of 74 leprosy patients recruited into the study, 22 returned and were tested at least three times. Nine patients were classed as 'paucibacillary' (PB: four TT, five BT), and 13 as 'multibacillary' (MB: three BB, seven BL, three LL). These subjects were all Nepali, 19 male and three female, mean age 31 years (range 12-68 years), who had received 0-8 doses (median one dose) of MDT prior to the study; 10 patients were untreated. Patients who experienced reactions were not retested until at least a month after finishing prednisolone (or thalidomide) treatment, to allow the immunosuppressive effects of the drug to diminish. Two patients (one BL, one LL) developed or remained in type 2 reaction during the study and were excluded from analysis.

Twelve patients (seven $\mathrm{PB}$, five $\mathrm{MB}$ ) remained free of the clinical signs of reaction during the study. Both PB and MB patients made similar responses to PHA, but the MB group made overall lower responses to PPD, and low or no responses to MLS (Table 2). Compared to the Nepali endemic group, response variation in these patient groups was higher to PPD, slightly lower to MLS (PB patients) and similar to PHA. Therefore, active clinical leprosy did not appear to increase the variability of T-cell responses to $M$. leprae above what would be 
expected in healthy subjects. Increases in T-cell response prior to onset of reaction would have to be significantly above these 'normal' limits of variation to be noticeable. Development of a positive MLS response may be significant in MB patients who made low or no responses to this antigen.

Four patients were in type 1 reaction on their first test; their responses to PPD and MLS over the course of the study are shown in Figure 4(a). Three patients showed higher responses to MLS at this time than on subsequent testing which was significantly greater than would be anticipated from normal variation' (BT28-74\% higher, BB2-300\% higher, BL14-a positive response which then became negative). One patient (BL29) made no response to MLS both during and after reaction. Responses to PPD were either similar or lower during/post-reaction; PHA responses were within the limits of anticipated variation throughout. Change due to reaction is, however, more difficult to assess in these patients in whom pre-reaction data is lacking.

Four patients developed type 1 reaction during the study (Figure 4b). One patient (BT27) showed an increase in proliferation response to MLS of over $200 \%$ compared to responses preceding and following the reaction. Responses to PPD and PHA did not vary significantly in this subject. The MB patients in this group showed consistently low or negative responses to MLS. Responses to PPD and PHA were relatively stable in these subjects, apart from patient BB4, who showed a distinct increase in response to PPD at the time of the reaction.

Although based on a small group of patients, these results suggest that detectable increases in in vitro responses to M. leprae may be observed in PB leprosy patients undergoing type 1 reaction, but multibacillary patients continue to make negative responses.

SEQUENTIAL ANTI-PGL-1 ANTIBODY RESULTS IN NEPALI LEPROSY PATIENTS

Figure 5 presents the anti-PGL-1 antibody titres measured in the same patients over the course of the study. In the group of patients who did not go into reaction (Figure 5a), anti-PGL-1 titres were generally higher in the MB patients, lower in the PB patients, and showed an overall fall in titre with treatment in agreement with previous studies ${ }^{24}$, although this was not a significant decline. All patients had only recently started treatment, apart from one LL patient, who had received eight doses of MDT. Of the patients who developed type 1 reaction during the study (Figure 5b), anti-PGL-1 antibody responses were not obviously higher prior to or during the reaction. Two patients had received MDT treatment prior to the study: BL17 (six doses), who showed signs of reaction on test 2, and LL7 (eight doses), who showed signs of reaction on his final test. Measurement of anti-PGL-1 antibodies cannot therefore be used to predict type 1 reactions.

\section{Discussion}

The use of a whole blood assay, requiring only a small volume of blood, made possible longitudinal studies of in vitro T-cell (proliferation and IFN $\gamma$ ) responses to mycobacterial antigens and mitogen in the UK and Nepal. The assay itself was found to be reproducible, with a standard dose of antigen $(10 \mu \mathrm{g} / \mathrm{ml})$ giving consistently optimal responses. Variations in responses were found to be independent of lymphocyte number in culture, in agreement with other studies. ${ }^{25,26}$

Previous studies have used separated peripheral blood mononuclear cell (PBMC) assays 
PPD
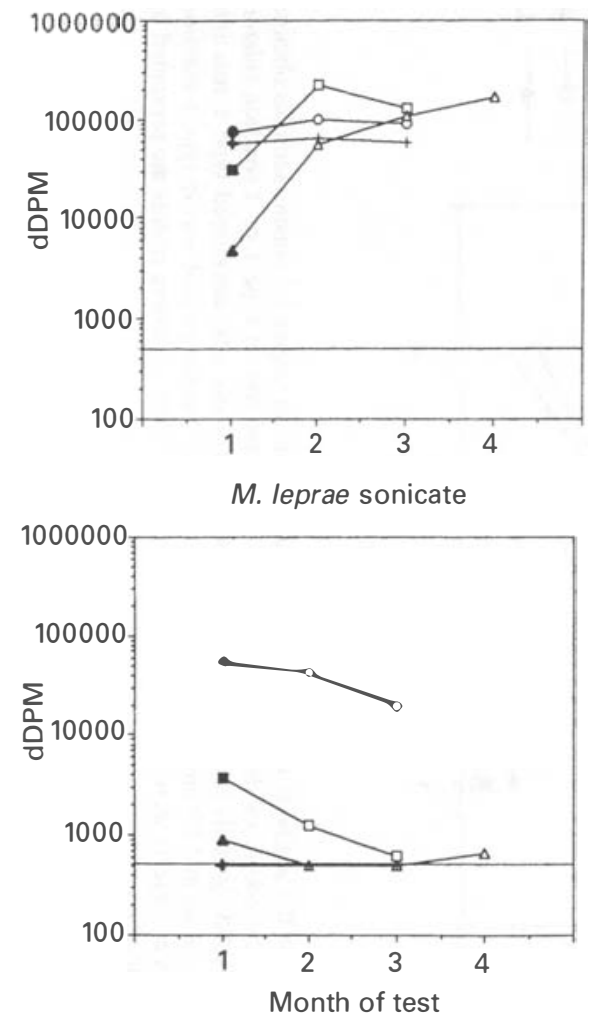

(b) Leprosy patients devloping type 1 reaction PPD
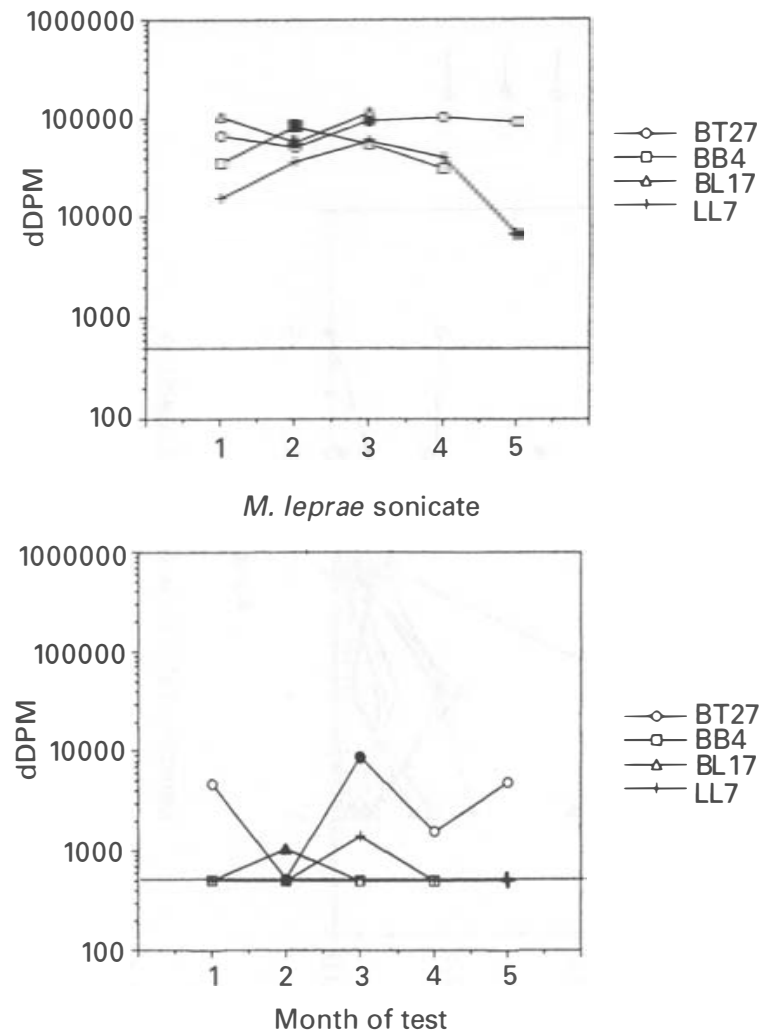

Figure 4. Proliferation responses (dDPM) to PPD and MLS (at $10 \mu \mathrm{g} / \mathrm{ml}$ ) in sequential whole blood cultures from leprosy patients (a) in type 1 reaction on the first test or (b) who developed type 1 reaction during the course of the follow-up study. Each symbol represents one patient (identified by leprosy classification and ID number); solid symbols indicate that the patient was in type 1 reaction at the time of testing. 
(a) Leprosy patients without type 1 reaction

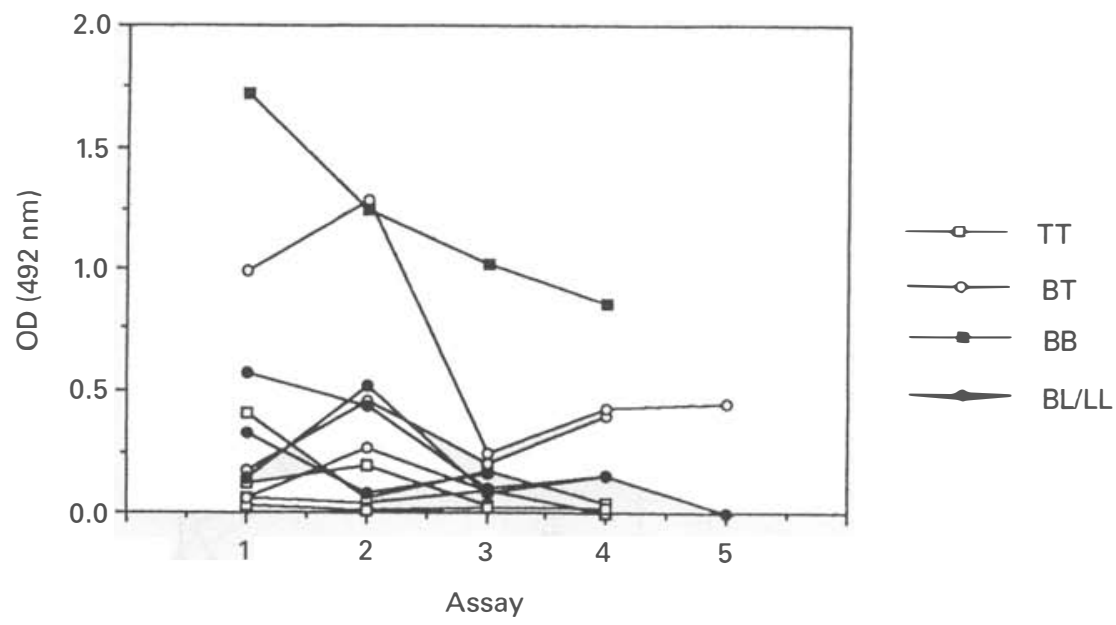

(b) Leprosy patients with type 1 reaction

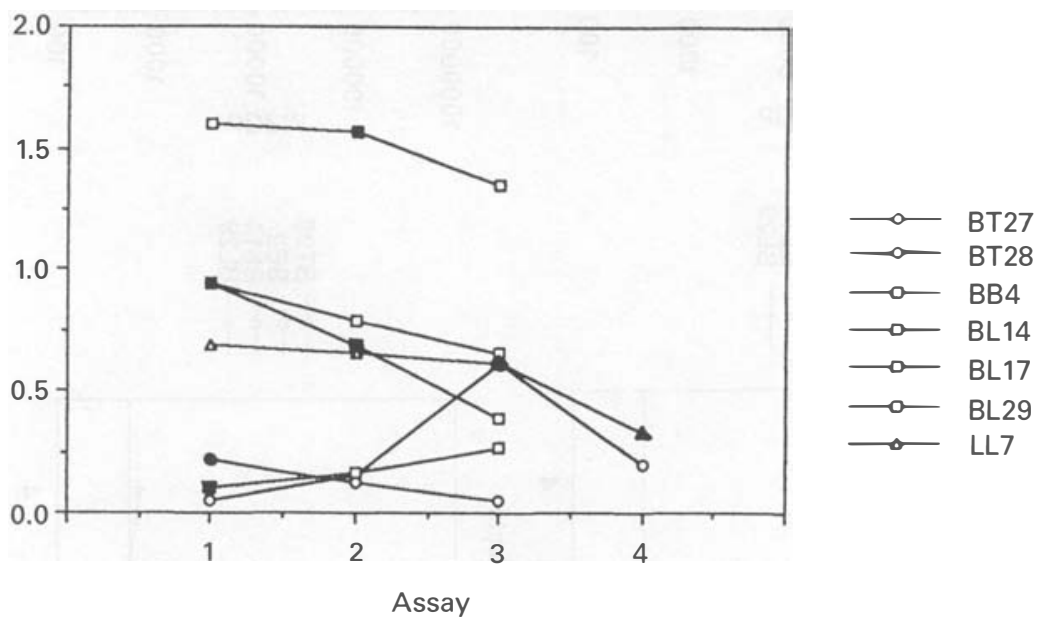

Figure 5. Anti-PGL1 antibody measurements (OD at $492 \mathrm{~nm}$ ) in sequential plasma samples obtained from leprosy patients during the course of the study. (a) Patients who were free of type 1 or 2 reaction (identified by leprosy classification, solid symbols represent MB patients); (b) patients who developed type 1 reaction (identified by leprosy classification and ID number, solid symbols indicate that the patient was in type 1 reaction at the time of testing). As a few subjects were not tested for anti-PGL1 on every occasion, results are presented by 'assay' rather than by 'month of test'.

to carry out longitudinal studies of T-cell proliferation responses to $M$. leprae in leprosy contacts at risk of developing leprosy, ${ }^{27}$ leprosy patients receiving immunotherapy ${ }^{28}$ and leprosy patients undergoing reactions ${ }^{23}$ to investigate changes in the immune response that correlate with alterations in the clinical symptoms of the subject. However, none to our knowledge have studied the variation in the 'normal' T-cell response to $M$. leprae antigens in healthy subjects, which must be taken into consideration both when interpreting results from 
single measurements collected in cross-sectional studies of T-cell immunity in leprosy, or when interpreting changes in immune responses during clinical leprosy, for example in reaction studies. In addition, results are usually presented graphically, and analysed as changes between positive and negative responses to $M$. leprae. In this study, we have attempted to quantify variability in the magnitude of T-cell responses over time, so that differences between study groups could be analysed for significance.

The study of control donors in the UK found responses to $M$. leprae sonicate, M. tuberculosis PPD, and the mitogen PHA, to be relatively stable in that an individual consistently responded or did not respond. Calculation of coefficients of variation for this data showed variation of the magnitude of response to be approximately $30-40 \%$. IFN $\gamma$ responses were found to be more variable than proliferation responses.

Control subjects in a leprosy endemic area of Nepal showed more variable proliferation responses to MLS and mitogen than the UK controls. As identical protocols were used in each location, greater variation in Nepal may reflect current exposure to $M$. leprae, or other infectious agents. This baseline variation was comparable with that seen in responses of leprosy patients who were free of reactions during the study. Active leprosy cases receiving chemotherapy might be expected to show more variable responses due to the release of antigens from dead $M$. leprae in the tissues (one mechanism proposed to underlie reaction onset), but this did not appear to be the case.

A significant increase in response to $M$. leprae sonicate above the baseline level of variation was seen in two paucibacillary leprosy patients who experienced type 1 reactions during the study. In one case, this coincided with a significant increase in response to PPD, otherwise PPD responses were consistently positive but did not increase significantly in these patients. No significant changes were observed in mitogen responses in any of the patient groups. This indicates that the response to $M$. leprae in particular rather than mycobacterial antigens or mitogen in general may be predictive of reaction onset.

The multibacillary patients did not respond to $M$. leprae sonicate even when in reaction, which indicates that in vitro responses to $M$. leprae may not be useful for anticipating onset of reactions in multibacillary patients. It may be that significant inflammatory changes at reaction onset are only apparent in the T-cells of the lesions, rather than in the blood, of these patients. Anti-PGL-1 antibody titres did not change in the patients undergoing reaction, so although high titres are associated with a tendency to develop reactions, ${ }^{20,21}$ increased anti-PGL-1 antibody titres would not appear to be directly predictive of reaction onset.

If the increase in response to $M$. leprae observed in the two BT leprosy patients in reaction in this study is a real effect, it remains to be established if this occurs before the clinical appearance of a reaction; neither of these patients showed increased responses a month prior to reaction becoming apparent. If the two events occur simultaneously, immediate treatment with steroid would still not completely prevent nerve damage due to reaction. In addition, close monitoring of patients using a test which does not give a result for a number of days is not feasible in an area such as Nepal. Patients often make long journeys for brief visits to the clinic and may not return for several months, making sequential testing of patients difficult as this study found. In conclusion, a whole blood assay to measure in vitro T-cell responses to $M$. leprae antigens is a useful and simple way of monitoring cell mediated immune responses in leprosy patients, but is probably not practical as a diagnostic tool for predicting and preventing reactions in leprosy.

This study has clarified the 'normal' baseline variation in T-cell proliferation and IFN $\gamma$ responses to $M$. leprae antigens in a range of subject groups. The whole blood assay could 
now be used in a larger longitudinal study of leprosy patients, possibly using more defined antigens and a range of cytokines as response markers, and in conjunction with studies of immunological markers in the lesions, to investigate in more detail the immune mechanisms in leprosy that may help to understand the onset, and eventually reduce the incidence, of type 1 and 2 reactions.

\section{Acknowledgements}

This work was supported by the Hospital and Homes of St Giles, UK, with the co-operation of The Leprosy Mission International. The authors would like to thank the staff of the Mycobacterial Research Laboratories and Anandaban Hospital for their assistance with study subject recruitment and technical support for these studies, and Dr J. Wheeler, LSH\&TM, for advice on statistical analysis.

\section{References}

${ }^{1}$ Petrovsky N, Harrison LC. Diurnal rhythmicity of human cytokine production. A dynamic disequilibrium in T helper cell type 1/T helper cell type 2 balance? J Immunol, 1997; 158: 5163-5168.

2 Rook GAW, Hernandez-Pando R, Lightman SL. Hormones, peripherally activated prohormones and regulation of the Th1/Th2 balance. Immunol Today, 1994; 15: 301-303.

3 Piccinni M-P, Giudizi M-G, Biagiotti R, Beloni L, Giannarini L, Sampognaro S, Parronchi P, Manetti R, Annunziato F, Livi C, Romagnani S, Maggi E. Progesterone favors the development of human T helper cells producing Th2-type cytokines and promotes both IL-4 production and membrane CD30 expression in established Th1 cell clones. J Immunol, 1995; 155: 128-133.

${ }^{4}$ Lucey DR, Clerici M, Shearer GM. Type 1 and type 2 cytokine dysregulation in human infectious, neoplastic and inflammatory diseases. Clin Microbiol Rev, 1996; 9: 532-562.

5 Bloemena E, Roos MTL, Van Heijst JLAM, Vossen JMJJ, Schellekens PTA. Whole-blood lymphocyte cultures. $J$ Immunol Methods, 1989; 122: 161-167.

${ }^{6}$ Frankenburg S, Kofsky Y, Gross A. In vitro secretion of cytokines by human mononuclear cells of individuals during and after cutaneous leishmaniasis infection. Parasite Immunol, 1993; 15: 509-512.

7 van Deuren M, van der Ven-Jongekrig J, Demacker PNM, Bartelink AKM, Van Dalen R, Sauerwein RW, Gallati H, Vannice JL, Van der Meer JWM. Differential expression of proinflammatory cytokines and their inhibitors during the course of meningococcal infections. J Infect Dis, 1994; 169: 157-61.

8 Weir RE, Morgan AR, Britton WJ, Butlin CR, Dockrell HM. Development of a whole blood assay to measure T cell responses to leprosy: a new tool for immuno-epidemiological field studies of leprosy immunity. J Immunol Methods, 1994; 176: 93-101.

9 Harboe M. Overview of host-parasite relations. In: Leprosy, Hastings RC, ed. Churchill Livingstone, Edinburgh, 1994, pp. 87-112.

10 Naafs B. Treatment of reactions and nerve damage. Int J Lepr, 1996; 64: S21-S28.

11 Bjune G. Reactions in leprosy. Lepr Rev, 1983; Special issue: 61S-67S.

12 Sampaio EP, Moreira AL, Sarno EN, Malta AM, Kaplan G. Prolonged treatment with recombinant interferon gamma induces erythema nodosum leprosum in lepromatous leprosy patients. J Exp Med, 1992; 175: $1729-1737$.

13 Sampaio EP, Samo EN, Gallily R, Cohn ZA, Kaplan G. The influence of thalidomide on the clinical and immunologic manif estation of erythema nodosum leprosum. J Infect Dis, 1993; 168: 408-414.

14 Filley E, Andreoli A, Steele J, Waters M, Wagner D, Nelson D, Tung K, Rademacher T, Dwek R, Rook GAW. A transient rise in agalactosyl IgG correlating with free interleukin 2 receptors, during episodes of erythema nodosum leprosum. Clin Exp Immunol, 1989; 76: 343-347.

15 Sehgal VN, Bhattacharya SN, Shah Y, Sharma VK, Gupta CK. Soluble interleukin-2 receptors: levels in leprosy, and during and after type 1 (lepra) and type 2 (ENL) reactions. Lepr Rev, 1991; 62: 262-268.

16 Scollard DM, Theetranont C, Suriyanon V, Bhoopat L, Rangdaeng S, Thamprasert K. Measurement of cellular and soluble immunologic changes in vivo in human leprosy lesions. Acta Leprol, 1989; 7: 149-152.

17 Saha K, Bhatnagar A, Sharma VK, Chakrabarty AK. Enzyme immunoassay of serum $\beta$-2-microglobulin levels in various histological forms of leprosy with special reference to its elevation in type I and type II Jepra reactions. J Clin Microbiol, 1985; 21: 658-661. 
18 Kifayet Q, Shahid F, Lucas S, Hussain R. Erythema nodosum leprosum is associated with up-regulation of polyclonal IgG1 antibody synthesis. Clin Exp Immunol, 1996; 106: 447-453.

19 Sarno EN, Sampaio EP. The role of inflammatory cytokines in the tissue injury of leprosy. Int J Lepr, 1996; 64: S69-S74.

20 Roche PW, Theuvenet WJ, Britton WJ. Risk factors for type 1 reaction in borderline leprosy patients. Lancet, 1991; 338: 654-657.

${ }^{21}$ Roche PW, Le Master J, Butlin CR. Risk factors for type 1 reactions in leprosy. Int J Lepr, 1997; 65: 450-455.

22 Barnetson RS, Bjune G, Pearson JMH, Kronvall G. Antigenic heterogeneity in patients with reactions in borderline leprosy. BMJ, 1975; 4: 435-437.

${ }^{23}$ Bjune G, Barnetson RS, Ridley DS, Kronvall G. Lymphocyte transformation test in leprosy; correlation of the response with inflammation of lesions. Clin Exp Immunol, 1976; 25: 85-94.

24 Roche PW, Britton WJ, Failbus SS, Neupane KD, Theuvenet WJ. Serological monitoring of the response to chemotherapy in leprosy patients. Int J Lepr, 1993; 61: 35-43.

${ }^{25}$ Leroux M, Schindler L, Braun R, Doerr HW, Geisen H, Kirchner H. A whole-blood lymphoproliferation assay for measuring cellular immunity against Herpes viruses. J Immunol Methods, 1985; 79: 251-262.

26 Elsasser-Beile U, Von Kleist S, Gallati H. Evaluation of a test system for measuring cytokine production in human whole blood cell cultures. J Immunol Methods, 1991; 139: 191-195.

27 Sampaio EP, Moreira AL, Kaplan G, Alvim MFS, Duppre NC, Miranda C, Sarno EN. Mycobacterium lepraeinduced interferon-gamma production by household contacts of leprosy patients: association with the development of active disease. J Infect Dis, 1991; 164: 990-993.

${ }^{28}$ Rada E, Ulrich M, Aranzazu N, Santaella C, Gallinoto M, Centeno M, Rodriguez V, Convit J. A longitudinal study of immunologic reactivity in leprosy patients treated with immunotherapy. Int J Lepr, 1994; 62: 552-558. 